Who gets more out of sport? The role of value and perceived ability in flow and identityrelated experiences in adolescent sport.

Applied Developmental Science

December 2015.

Catherine F Drane \& Bonnie L. Barber

School of Applied Psychology, Menzies Health Institute Queensland, Griffith

University; Murdoch University 


\section{Who gets more out of sport? The role of value and perceived ability in flow and identity-related experiences in adolescent sport.}

Adolescents spend much of their 'out of school' time participating in extracurricular sport activities which can be thought of as distinct learning contexts offering adolescents a platform for personal growth and development. There is extensive evidence for the role of extracurricular sport participation in adolescent development (Barber, Abbott, Blomfield, \& Eccles, 2009; Feldman \& Majasko, 2005; Marsh \& Kleitman, 2002), with participation positively associated with indicators of academic performance (Eccles \& Barber, 1999; Fredricks \& Eccles, 2006), emotional regulation, initiative, and team work (Larson, Hansen \& Moneta, 2006), and development of values such as responsibility, conformity, persistence, courage, and self-control (Hansen \& Larsen, 2007; Kleiber \& Kirshnit, 1991).

Most Australian adolescents participate in sport, with $60 \%$ participating in sport outside of school hours (Australian Bureau of Statistics, 2012). Given the normative nature of sport participation, much research has examined the role organized sports play in the development of age-appropriate competencies (Barber, Stone, \& Eccles, 2010). Although the benefits of sport participation are well documented, not all adolescents have positive experiences. Why do some benefit, whereas others do not? To have positive experiences requires more than simply going through the motions of what is required for sport participation. Intrinsic mechanisms and motivations play an important role as well.

It is important to consider the quality of extracurricular experiences for each individual, and to identify conditions in which adolescents flourish and thrive (Theokas et al., 2005). The quality of experience may make the difference between a positive or negative developmental outcome, and may account for variations in psychological well-being (Hansen et al., 2003). Eccles and her colleagues argue that an individual's choice of an activity, persistence, and performance can be explained by their own beliefs about how well they will 
do in the activity and the extent to which they value the activity (Eccles et al., 1993;

Wigfield, 1994; Wigfield \& Eccles, 1992). Therefore, it is possible that adolescents who are fully engaged in their sport, that is, psychologically invested and motivated, who have confidence in their ability to perform well along with expectations for success, and who attach value to playing their sport, reap greater psychological benefits than less invested or confident adolescents.

A focus on the interplay between attributes of young people and the settings in which they are engaged is crucial for understanding contexts that foster positive development. Contemporary developmental systems theory emphasises processes involved in the changing relations between developing individuals and their contexts (Lerner \& Castellino, 2002). Likewise, person-environment fit theory emphasises the impact the environment has on adolescent development, and considers how the changing needs of the young person can interact with attributes of the environment to shape developmental pathways (Eccles et al., 1993). The person-environment fit theory provides an overarching framework to highlight the importance for adolescents to have a match between their changing developmental needs and their environment. During adolescence, emotional, cognitive and social needs shift as new developmental tasks, such as autonomy and identity formation, become salient. Contexts that are responsive to these developmental needs will continue to motivate and engage adolescents as they mature (Eccles et al., 1993). Adolescents whose environments do not afford opportunities well aligned for building competence and sense of self are less likely to do well or be motivated than adolescents whose contexts are more optimally matched to their developmental needs (Eccles, 2008; Eccles \& Midgely, 1989; Eccles et al., 1993). Applying both of these theories specifically to sport suggests that a fit is required between the changing developmental needs of the individual and the sport context so that growth and challenge can occur. More specifically, if the need is to feel competent in their chosen sport, adolescents 
with well aligned self-concepts should find the sport setting satisfies that need. Likewise, those who think sport is important would find such a context validating.

\section{Developmental Experiences in Sport}

Researchers have begun to investigate the underlying processes of extracurricular activity participation and in doing so have recognized the role organized activities play in affording adolescents a range of developmental experiences. Developmental experiences can be thought of as developmental opportunities which promote key developmental tasks. These tasks include acquiring habits of both physical and psychological health (Eccles et al., 2003).

One developmental experience associated with activity participation is identity exploration, which is a crucial task in adolescence. If the identity formation process is successful, the adolescent emerges more individuated with an understanding of who they are and how they fit into the world (Erikson, 1968; Sharp, Coatsworth, Darling, Cumsille, \& Ranieri, 2007). Furthermore, the formation of a cohesive identity is associated with healthier social and psychological functioning and lower rates of problem behaviour (De Haan \& MacDermid, 1999; Jones \& Hartmann, 1988; Jones, Hartmann, Grochowski, \& Glider, 1989; Waterman, 1992).

Research on identity formation has recognized the role sport participation plays as a context for identity work (Barber, Stone, Hunt, \& Eccles, 2005; Eccles \& Barber, 1999; Eccles et al., 2003; Hansen et al., 2003; Larson, 2000; Larson, Hansen, \& Moneta, 2006; Waterman, 1990). In order to evaluate how participation in organized sport activities contributes to adolescent development, researchers have examined the role of sport participation in the development of age-appropriate competencies (Collins, Maccoby, Steinberg, Hetherington, \& Bornstein, 2000). Larson, Hansen \& Moneta (2006) suggest that extracurricular sports stand out from other school contexts because they offer opportunities for adolescents to develop initiative, and learn new skills as well as emotional competencies. 
Acquiring competencies allows adolescents to tap into the resources that promote positive functioning (Eccles et al., 2003; Mahoney \& Bergman, 2002; Mahoney et al., 2006). A mechanism whereby sports may have a positive influence in adolescent development is through the validation of identity. When a sport confirms an adolescent's self-image, it can promote psychological well-being as well as school attachment (Eccles \& Barber, 1999).

In addition to identity work, sport also offers opportunities for flow experiences (Csikszentmihalyi \& Rochberg-Halton, 1981). Flow experiences are indicative of the fit between person and environment which promotes psychological health and well-being, a key developmental task of adolescence (Eccles et al., 2003; Lerner \& Lerner, 1987). Flow is regarded as a state of consciousness, where concentration becomes so focused that complete absorption in an activity occurs. Experiencing flow is intrinsically rewarding, resulting in a deep sense of enjoyment, harmony, and happiness (Csikszentmihalyi, 1990). Flow is a positive experience that is so intrinsically rewarding that individuals seek to repeat the experience, therefore flow can influence an individual's future motivation to remain in an activity long-term (Schuler \& Brunner, 2009). The flow experience is achieved when an individual is challenged beyond their average experience, with their personal skills consistent with the level of challenge. In other words, there is a balance between high challenge and high skill level, and the combination of both of these produces flow. However, exactly what is considered challenging is based on an individual's perception of challenge, and perception of skill level, rather than an objective assessment. Therefore, the ability to self-assess skills is paramount to experiencing flow. Staying in flow requires an individual to take on increasingly greater challenges and consequently to re-assess their skill level (Csikszentmihalyi \& Csikszentmihalyi, 1988). Flow typically occurs in clearly structured activities in which the level of challenge and skill can be varied and controlled, such as sport. 
Therefore, sport becomes an ideal platform for understanding under what circumstances adolescents experience flow.

Much of the literature on flow in sport has focused on elite athletes (Jackson \& Eklund, 2002; Jackson, Ford, Kimiecik, \& Marsh, 1998; Jackson \& Marsh, 1996;) in order to understand the role that positive experiences play in achieving high levels of sport performance (Jackson, 1995, 1996; Jackson \& Roberts, 1992). These studies demonstrate that elite athletes report experiencing flow during both practice sessions and competition, and clearly value experiencing flow as part of their overall sport involvement. Furthermore Stein, Kimiecik \& Jackson (1995) examined flow in participants in recreational, non-elite, sport contexts and found support for the flow experience, suggesting that the experience of flow is not confined to the elite athletes and can occur for those developing sport skills. The current study thus incorporates flow, as well as identity work, as key developmental experiences in adolescent sport.

\section{Individual Differences among Athletes}

Adolescents who spend time participating in organized activities on a regular basis are typically fuelled by intrinsic motivations (Mahoney, Harris \& Eccles, 2006). Adolescents' motivation can be seen as influencing the degree of psychological engagement in organized activities and the extent to which participation yields developmental experiences. Hansen and Larson (2007) evaluated four factors hypothesized to be associated with more positive experiences in organized youth activities. Developmental experiences were measured using the Youth Experiences Survey. One of the four factors found to amplify developmental experiences was motivation, with adolescents who reported more motivation, in the form of enjoyment, reporting higher rates of developmental experiences in organized activities, including sport (Hansen \& Larson, 2007). Adolescents are motivated to participate in organized activities for intrinsic reasons beyond enjoyment. According to motivation 
theories, the strongest predictors of participation in activities should be ability beliefs and interest (Eccles et al., 1993; Ryan \& Deci, 2000).

When considering adolescent motivation in sport, ability and value beliefs play an important role. The expectancy-value theory suggests that individuals' choice of activity, persistence in the activity, and overall performance can be explained by beliefs about how well they will do in the activity and the extent to which they value the activity (Eccles et al., 1983; Wigfield, 1994; Wigfield \& Eccles, 1992). Ability self-concept refers to an individual's perceived ability or competence at a given activity and is regarded as an important aspect of self-concept (Eccles et al., 1983; Wigfield, 1994; Wigfield \& Eccles, 1992). Attainment value is the importance students attach to a task as it relates to their concept of identity and their ideals or competence in a given field (Eccles et al., 1983; Wigfield, 1994; Wigfield \& Eccles, 1992). For example, adolescents who identify as athletes will set goals related to their sport. Those adolescents are then motivated to attain the goals, as they are associated with their understanding of 'who they are' (Barber et al., 2005; Eccles et al., 1983; Wigfield, 1994; Wigfield \& Eccles, 1992). Attainment value can be regarded as a mechanism that underpins choice and may highlight the importance of activity participation being voluntary. Personal performance expectations, including perceptions of ability, coupled with the value adolescents attach to an activity will not only contribute to their choice of activity but will also influence perceptions of experiences as developmentally facilitative, with opportunities for challenge and growth.

As children grow, they begin to develop mental images of who they are and who they would like to be (Eccles \& Harold, 1991). These images include such things as personal values, ideations of personality and capabilities, long-term plans/goals, conceptions of gender roles, and self-schema (Eccles \& Harold, 1991). Eccles et al. (1983) suggest that individuals will choose to participate in activities that they see as being compatible with their self-images 
and avoid activities that are inconsistent with these images. Applying the concept of attainment value and ability self-concept specifically to sporting activities suggests that if adolescents view a sport as requiring the characteristic of speed, they believe they are fast, and they want to confirm that they are fast, then the attainment value of the sport is high for those adolescents (Eccles \& Harold, 1991). The sport environment provides adolescents with the opportunities and the freedom to evaluate what interests them, where their talents lie and what they value. For each individual, some activities are more likely to promote identity formation than others. Eccles et al., (2003) describe these activities as having high “attainment value" or importance. Adolescents are more likely to choose a specific sport if they place high value on doing well and feel confident in their own ability to do well, in this sense, motivation provides a platform for forming an identity around sport (Eccles, 2009). Furthermore, when adolescents have confidence in their own abilities and value being good at a sport that provides new challenges and requires the use of new skills, they may experience a sense of deep enjoyment or flow. Attributing high value to being good at sport and playing at the limit of one's potential can be so intrinsically rewarding that individuals seek to experience it again and again.

\section{Participation Intensity and Age}

In general, as amount of time spent in structured activities increases, positive outcomes increase (Barber et al., 2010; Larson \& Verma, 1999). This link may be related to increased opportunities to experience the developmentally facilitative aspects of participation. For example, more hours spent in a particular sport may afford greater opportunities for selfreflection and deep concentration or flow. What is not well understood is whether the intensity of participation may also condition the relation between individual attributes and sport experiences. To the extent that self-beliefs such as values and expectancies align well to the particular sport context, such congruence may be most auspicious for those who spend 
more time in those settings. Increased exposure is likely to be more beneficial in situations where the experiences align with one's self image, relative to spending greater nonpersonally relevant activity time. Whether having more time invested in sport increases the alignment of motivational beliefs with developmental experiences in sport has not been studied previously. This study tests those links.

Adolescence is a period of growth both physically and psychologically during which adolescents are gradually acquiring abilities and capabilities (Larson, 2000). Specifically, Erikson argued that certain tasks become primary at different ages or stages of development, and he highlighted, in particular, the developing capacity for self-reflection as a feature of adolescence (Erikson, 1968). An important consideration of the adolescent period is the impact that the final school year may have on both developmental experiences and motivation. Adolescents in grade 12 are preparing to transition out of high school and these students may be particularly focused on the developmental task of identity formation. It is possible that the alignment of self-beliefs and experiences becomes particularly salient at this time of transition. For this reason grade 12 sport participants were selected for this study and were compared to a cohort of grade 9 sport participants.

\section{Current Study}

We aim to understand how motivational beliefs of adolescents predict developmental experiences in their sport. In particular, the investigation of attainment value (the importance attached to a task) and ability self-concept (how good you think you are at a task) may help to explain differences in experiences reported by athletes. The current study examined associations between attainment value, ability self-concept, intensity of participation, age, and the developmental experiences of identity formation and flow in youth sport.

We predicted that higher levels of attainment value and ability self-concept would be associated with higher levels of identity formation and flow experiences for adolescents. 
Previous research has shown that dosage of participation is developmentally important for adolescents in the later stages of development (Larson \& Verma, 1999), thus, we tested whether or not intensity and age jointly conditioned the association between attainment value and experiences, and ability self-concept and experiences in sport. That is, we predicted three-way interactions between attainment value, intensity and age, as well as ability selfconcept, intensity and age.

\section{Method}

\section{Participants}

Participants were drawn from the Youth Activity Participation Study (YAPS) of Western Australia as part of a larger longitudinal study of adolescent extracurricular activities and developmental outcomes. The YAPS participants were from 34 government (45.9\%) and non-government (54.1\%) high schools, from metropolitan (63.3\%) and regional (36.7\%) areas across Western Australia. The sample consisted of 1,628 students: 954 in grade nine and 674 in grade twelve $\left(M_{\text {age }}=15.22, S D_{\text {age }}=1.52\right.$, Range $_{\text {age }}=13-18$ years $)$.

\section{Measures}

Sport Participation. Adolescents' structured extracurricular sport involvement was assessed using measures adapted from previous research (Barber et al., 2005); to reflect Australian youth sport participation (Blomfield \& Barber, 2009). The self-report survey included a checklist for reporting extracurricular sport participation which included a list of 24 sports (e.g., hockey, soccer). Youth were asked to check all of the sports in which they were involved during the past year, with a space for 'other' if a sport was not present in the list. Youth were also asked to designate which sport they spent the greatest number of hours playing; this sport was their 'target' sport. The most common target sports listed by participants were netball, football and athletics. All questions asked in this study were in 
relation to the target sport. The target sports consisted of both school-based (63.9\%) and community-based $(36.1 \%)$ sports.

Developmental Experiences in Sport. To assess adolescent experiences in sport, youth were asked a series of questions about their perceived experiences in their 'target' sport, including identity formation and flow. The identity formation measure was based on the 'Youth Experiences Survey - YES' (Hansen et al., 2003; Dworkin et al., 2003). The fiveitem identity construct (Cronbach's $\alpha=.76$ ) was used in the interest of model parsimony (Larson, Hansen \& Moneta., 2006) and measured identity exploration using 3 items (e.g., tried doing new things) and identity reflection using 2 items (e.g., this activity got me thinking about who I am). Responses were rated on a 4-point scale, ranging from $1=$ 'Not at all' to $4=$ 'Yes definitely'. The 3 flow experience items were taken from Tiggemann $\&$ Slater (2001), developed to operationalise Csikszentmihalyi's (1990) description of the common characteristics of flow experiences (Cronbach's $\alpha=.89$ ): I become so involved in this sport that I lose track of time; During this sport I feel so involved that nothing seems to matter; I concentrate so intensely that I can't think about anything else. The responses were rated on a 7 -point scale, with $1=$ 'Never' to $7=$ 'always'.

Motivation. To assess adolescent motivation in sport, youth were asked a series of questions about their motivations in their 'target' sport, including attainment value and ability self-concept. (Eccles, 1987; Eccles et al., 1983). Attainment value was measured using 1 item: How important is it to you to be good at this sporting activity? Responses were rated on a $1-7$ scale, with 1 representing 'not at all important' to 7 indicating 'very important'. Ability self-concept was measured using 1 item: Compared to other kids your age, how good do you feel you are at this sport? Responses were rated on a $1-7$ scale, with 1 representing 'one of the worst' to 7 indicating 'one of the best'. 
Moderator: Intensity of Participation. Intensity of participation in the 'target' sport was assessed using a question in which adolescents reported: How many hours per week do you spend in this activity? A centered score for intensity of participation was also calculated prior to creating the interaction terms.

\section{Procedure}

Ethical approval for this study was obtained from the Murdoch University Human Research Ethics Committee, the Western Australian Department of Education and the Catholic Education Office. In order to participate, informed parent and student consent was required. The survey was administered at school over a 40-minute session, administered via iPads connected to a wireless intranet. Participants were informed of the confidentiality of their responses and reminded that participation was voluntary.

\section{Results}

Our primary research aim was to examine how attainment value and ability selfconcept were related to experiences of identity and flow in sport, and test whether intensity of participation moderated these relations. All predictor scores were mean-centered to ensure each first-order coefficient has an interpretation that was meaningful (Cohen, Cohen, West \& Aiken, 2003). The necessary condition of model identification was satisfied for the measurement model with the number of independent parameters (17) being smaller than the independent covariance equations (36). A series of moderated regression analyses in SEM were conducted, using Amos 21, to examine the independent and interactive effects of attainment value, ability self-concept, and intensity of participation on experiences in sport. Figure 3.1 shows the structural model.

\section{Hypothesized Model.}

To evaluate the hypothesized model, it is necessary to determine whether the associations among indicators and latent variables in the model adequately reflect the 
observed associations in the data. Therefore, two models were considered in this study, the hypothesized model, which includes a moderating variable and interaction terms (Attainment value $\mathrm{x}$ Intensity; Ability self-concept $\mathrm{x}$ Intensity), and a second constrained model, with moderator and interaction terms fixed to 0 . The purpose of this is to test whether the proposed model better represents the relations between the constructs than the alternate model without moderation. The constrained model showed poor fit $\chi^{2}(73)=7679.08, p<.001 ;$ RMSEA $=$ $.25(90 \%$ C.I: $.25-.26), \mathrm{NFI}=.56, \mathrm{TLI}=.46, C F I=.57$. The hypothesized model with better fit was used in subsequent analyses $\chi 2(62)=599.32, p<.001 ; R M S E A=.07(90 \%$ C.I: $.07-$ $.08), \mathrm{NFI}=.96, \mathrm{TLI}=.96, \mathrm{CFI}=.97$.

Figure Error! No text of specified style in document.-1

Structural Equation Model showing the standardized regression coefficients for grade 9's and grade 12's (Grade 12's in parentheses).

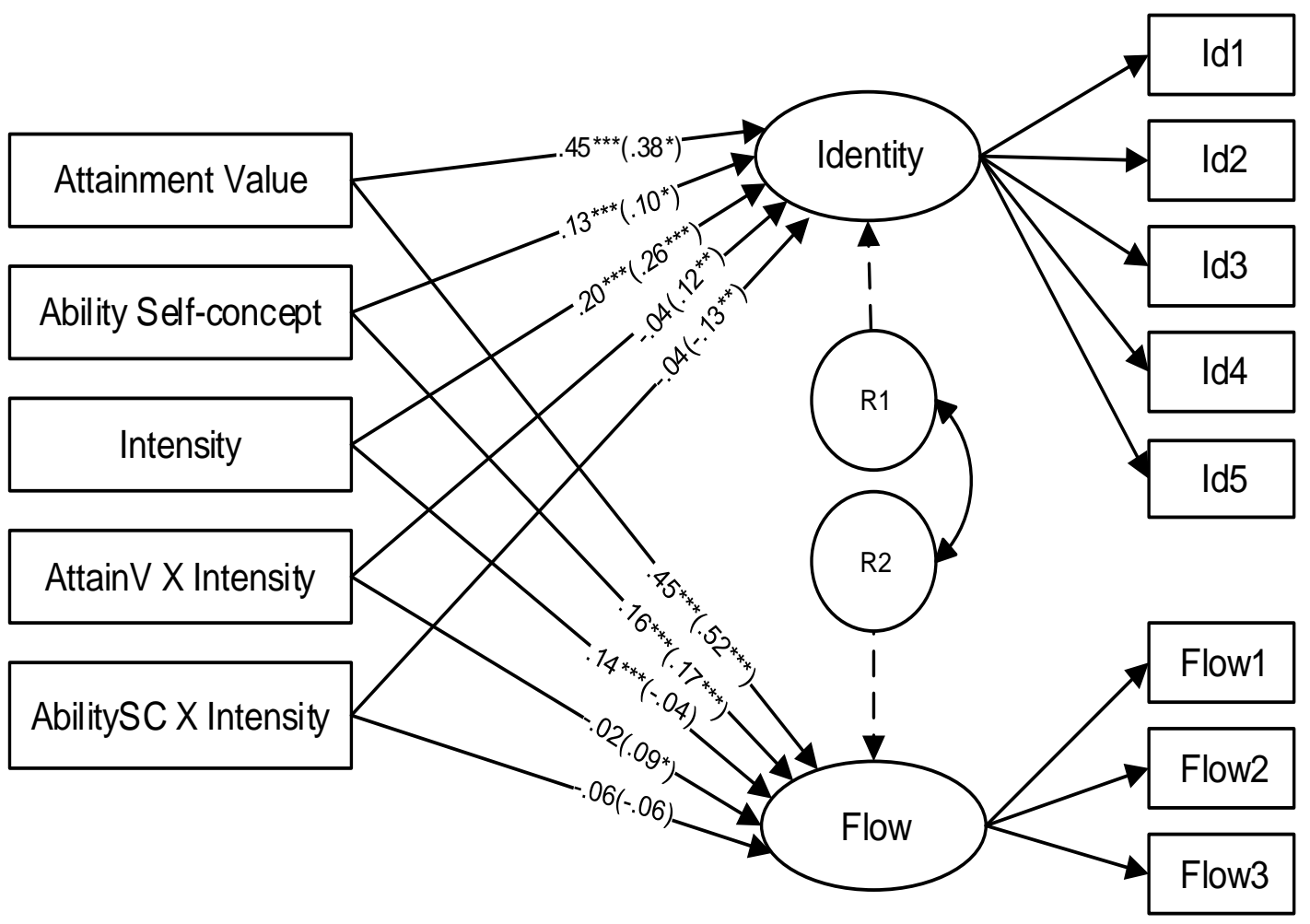

Note. Attain V = Attainment Value; AbilitySC = Ability Self-concept; ID = Identity; R = Residual. $* p<.05, * * p<.01, * * * p<.001$

\section{Multigroup Invariance Testing}


Multi-group analysis was initially run based on grade level, however, invariance testing revealed the identity and flow measurement models for grade 9 and 12 were invariant at the configural level but not at the structural level. Therefore the coefficients could not be compared across groups. These invariance results, suggesting that grade levels could not be directly compared makes sense developmentally. During different developmental stages, students are likely to interpret questions relating to their identity formation and flow experience differently. Given that we could not directly compare the strength of relations between age groups, two separate models were fit (grade 9 and grade 12). However no inferential comparisons were made between the two groups and only observations of patterns of interactions between the two models were made. Both structural models satisfied the condition for model identification, that is, for the grade 9 model, the number of independent parameters (42) were smaller than the independent covariance equations (91). Likewise, for the grade 12 model, the number of independent parameters (55) were smaller than the independent covariance equations (104). Table 3.1 shows the correlation matrix, means and standard deviations of all constructs in the two models. Given the large sample sizes, fit indices were used to determine model fit (Bollen, 1989). The grade 12 model fit was adequate according to the descriptive fit indices, $\chi 2(49, N=674)=150.04, p<.001, R M S E A$ $=.05(90 \%$ C.I: $.04-.07), \mathrm{NFI}=.96, \mathrm{TLI}=.95, C F I=.97)$. Likewise, the grade 9 model fit the data adequately, $\chi 2(49, N=954)=209.84, p<.001, R M S E A=.06(90 \%$ C.I: $.06-.07)$, $\mathrm{NFI}=.95, \mathrm{TLI}=.94, C F I=.96$. 
Table Error! No text of specified style in document. -1 Correlation matrix, means and standard deviations of constructs for grade 9 and 12 Adolescents.

\begin{tabular}{lccccccc}
\hline Variables & 1 & 2 & 3 & 4 & 5 & Means & $S D$ \\
\hline 1. Attainment Value & - & 0.60 & 0.28 & 0.50 & 0.59 & 5.32 & 1.25 \\
2. Ability self-concept & 0.53 & - & 0.33 & 0.42 & 0.46 & 5.15 & 0.99 \\
3. Intensity of participation & 0.28 & 0.27 & - & 0.37 & 0.15 & 9.54 & 6.12 \\
4. Identity & 0.59 & 0.43 & 0.35 & - & 0.59 & 2.65 & 0.55 \\
5. Flow & 0.58 & 0.45 & 0.29 & 0.69 & - & 4.74 & 1.27 \\
$\quad$ Means & 5.44 & 5.19 & 10.30 & 2.69 & 4.73 & - & - \\
$\quad$ Standard Deviations & 1.27 & 1.20 & 7.11 & 0.60 & 1.38 & - & -
\end{tabular}

Note. Grade 12's are presented on top diagonal of the matrix.

Model results

The results for the younger adolescents (grade 9) show significant positive direct effects between attainment value and ability self-concept and identity and flow. Higher levels of attainment value and ability self-concept were related to more experiences of identity and flow in sport. Further, intensity of participation was positively associated with identity and negatively associated with flow. None of the interaction terms were significant for grade 9 students.

The results for the older (grade 12) students show significant direct effects of attainment value and ability self-concept on identity and flow. Higher levels of attainment value and ability self-concept were related to more experiences of identity and flow in sport. Intensity of participation was also significantly associated with identity formation in sport. More hours in sport related to more identity-related experiences in sport. The intensity of participation to flow link was non-significant for grade 12 students. Three of the two-way interactions (attainment value $\mathrm{x}$ intensity predicting identity; attainment value $\mathrm{x}$ intensity 
predicting flow; ability self-concept $\mathrm{x}$ intensity predicting identity) were significant for the older adolescents, indicating that intensity of participation moderated the links between attainment value and identity and between attainment value and flow in sport, and between ability self-concept and identity. The fourth two-way interaction (ability self-concept $\mathrm{x}$ intensity predicting flow) was not significant.

\section{Probing Interactions}

We further probed the significant two-way interactions by plotting the simple slopes (Dawson \& Richter, 2006) at 1 standard deviation above and below the mean for intensity. The simple slopes tests for attainment value and flow was significantly different from zero at

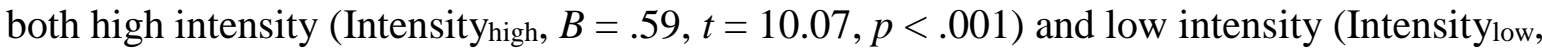
$B=.44, t=8.40, p<.001)$. Higher attainment value was related to more flow and the relationship was stronger for high intensity participation than for low intensity participation (See Figure 3.2).

Figure Error! No text of specified style in document.-2

Grade 12 flow experiences by attainment value and participation intensity.

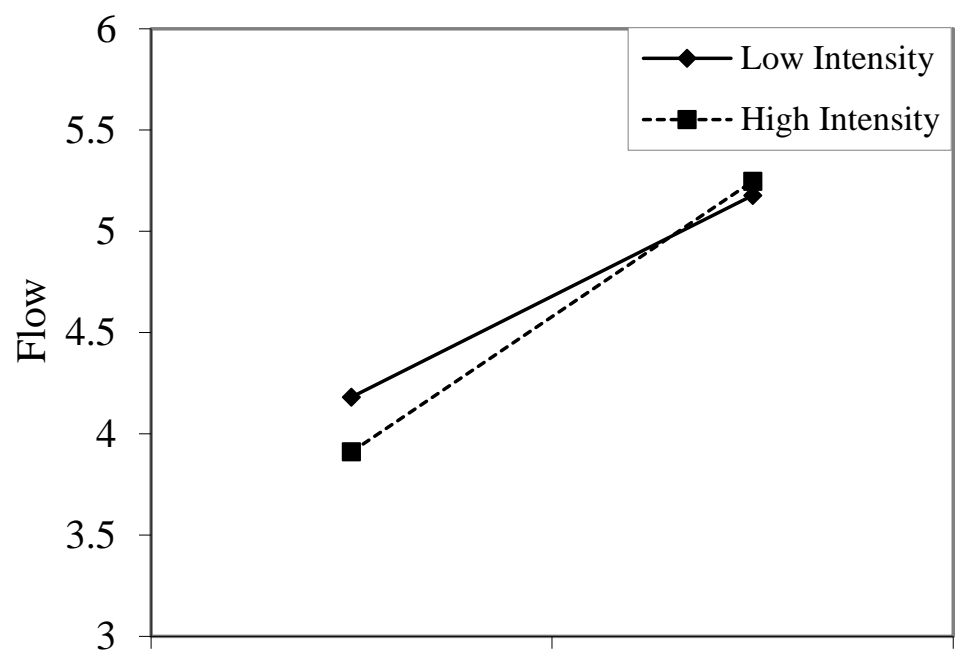

Low Attainment Value High Attainment Value

Note. Low Intensity $* * * p<.001 ;$ High Intensity $* * * p<.001$. 
The relationship between attainment value and identity was significantly different from zero at both high intensity (Intensity ${ }_{\text {high }}, B=.19, t=11.350, p<.001$ ) and low intensity (Intensitylow, $B=.11, t=8.77, p<.001$ ). The greater the attainment value the more identity related experiences participants reported (See Figure 3.3). Only in one group was having higher ability self-concept related to greater experiences of identity and that was in the lower intensity group. Simple slope analyses showed the relation between ability self-concept and identity was not significantly different from zero at high intensity (Intensity ${ }_{\text {high }}, B=.01, \mathrm{t}=$ $0.143, p=.886$ ) but was significantly different from zero at low intensity (Intensity low $_{\text {, }} B=$ $.09, t=2.614, p=.009)$. The relations between ability self-concept and identity was strongest for individuals who reported the lowest levels of intensity of participation in sport (See Figure 3.4).

Figure Error! No text of specified style in document.-3

Grade 12 identity experiences by attainment value and participation intensity

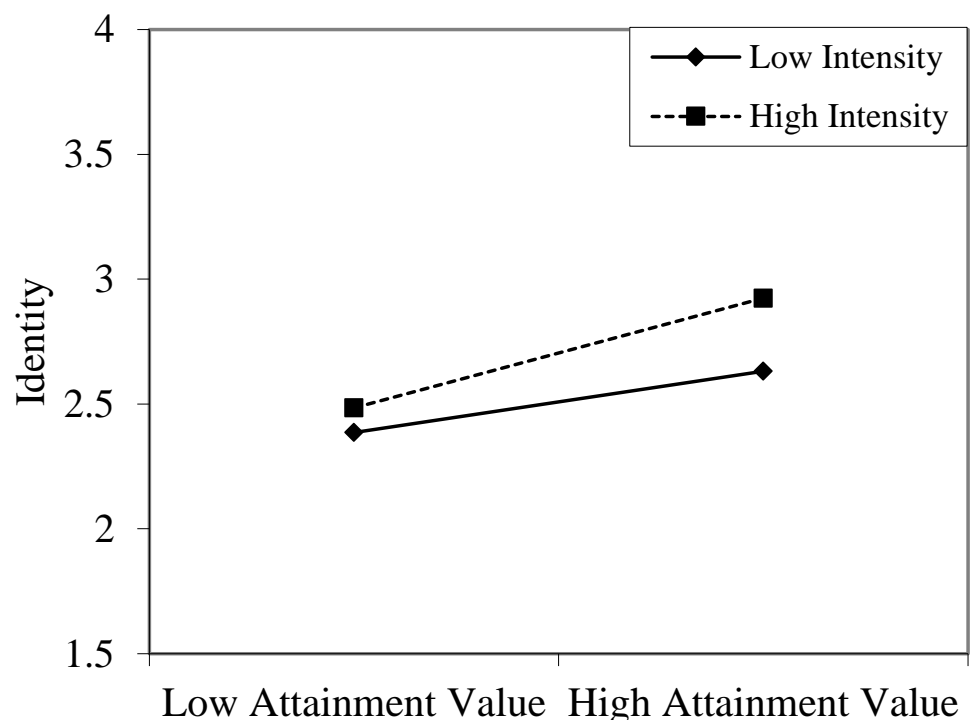

Note. Low Intensity $* * * p<.001 ;$ High Intensity $* * * p<.001$ 


\section{Figure Error! No text of specified style in document.-4}

Grade 12 identity experiences by ability self-concept and participation intensity

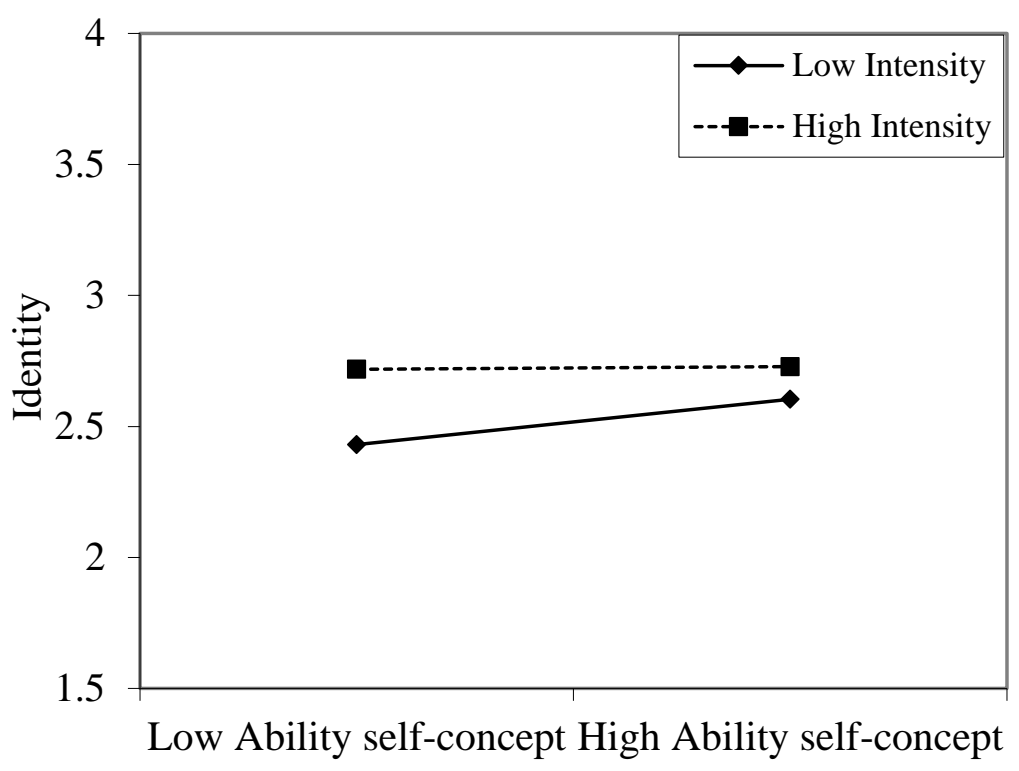

Note. Low Intensity ***p $<.001 ;$ High Intensity $p=.886$.

\section{Discussion}

The aim of this study was to examine the role of attainment value, ability self-concept, and intensity of participation in the developmental experiences of identity formation and flow in sport. We found that greater importance placed on sport was related to more positive developmental experiences. For older adolescents, this link was moderated by intensity of participation with those who played more hours showing the strongest relations between value and experiences. Adolescents with higher perceptions of their sport ability also reported more positive experiences in sport - that is, they reported more experiences of identity and flow. The link between ability self-concept and identity was moderated by intensity of participation for older adolescents; however, it was strongest at low levels of intensity.

As the models for younger and older adolescents were not invariant, we did not test the 3-way interactions between age, intensity, and motivational beliefs, and thus cannot make any inferential comparison between the two cohorts. We can say, however, that for both 
grade levels, it was the adolescents who were invested in their sport, valued it, and believed they were good at it, who benefited most in terms of developmental experiences. Such students reported greater flow, or sense of focus and concentration, which is important for well-being. Adolescents' need something in which to become engaged (Larson, 2000). Through opportunities for flow, sport may offer adolescents more opportunities to be completely involved and focused than other areas of their lives such a school classes or paid work offer, and our results suggest these positive experiences may be most common, at least among older youth, for those who are more motivated and personally aligned with their sport. These results are consistent with the evidence from sport psychology that indicates enjoyment of sport is linked to motivation (Scanlan, Babkes, \& Scanlan, 2005), and make a contribution by highlighting the importance of amount of time spent in the activity to the dynamics of person-environment fit.

Sport was also a context for exploring and reflecting on identity, particularly for those whose self-beliefs aligned well to their target sport in terms of values and self-concept of ability. However, not all sports will facilitate identity exploration and reflection equally for all students (Barber et al., 2005; Eccles \& Barber, 1999). The current study found that the extent to which an adolescent places high value on participating in their sport is facilitative of the identity process. When the environment is responsive to their changing needs, providing diversity or a range of sports to choose from, adolescents are likely to find a greater fit with their interests and abilities, and therefore have higher attainment value (Barber et al., 2005; Eccles \& Barber, 1999) perhaps leading to more positive developmental experiences, such as forming an identity around being an athlete. If the sport environment changes in developmentally regressive ways, then there is a mismatch that can result in a decline in motivation, interest, performance, and behaviour (Eccles \& Midgely, 1989; Eccles et al., 1993; Eccles, 2008). 
In addition, for older youth, how much they participated in their sport made a difference. Investing more hours in sport was related to more identity-related experiences. Further, for those young people who highly valued their target sport, the relationship with greater flow and identity experiences increased with amount of time spent playing. Towards the end of high school, the school workload increases with competing commitments; those who are still involved in sport and haven't dropped out tend to be very committed, highly invested, and fully engaged in their sport. For those who are highly motivated, spending more hours playing sport is a good fit to personal motivations. Such commitment can translate, as evident in our data, to having more positive and self-reflective experiences during sport participation. Interestingly, for older adolescents there was a stronger link between ability self-concept and identity experiences at low intensity than at high intensity. However, this effect can be interpreted to be one of a compensatory nature. At high intensity, regardless of self-concept, more identity experiences are reported than at low intensity. However, having high ability self-concept was related to identity experiences even at low intensity, when compared to lower ability self-concept. Perhaps because of the commitment required from these older students to maintain higher intensity participation, there were other motivations present to elicit identity-related experiences. Those reporting low levels of participation may dabble in a sport for other reasons, such as hanging out with friends, and when they don't consider themselves very good at sport, they don't reflect much about what it means to who they are.

\section{Policy Implications}

Findings from the current study hold several implications for policy. The growing evidence for benefits of sport participation may influence policymakers to conclude that such advantages are available to all regardless of motivational intent, regardless of personal choice. However, not everyone benefits or has positive experiences in sport. Placing low 
value on sport was related to less frequent flow experiences in our sample, suggesting that sport participation pushed by parents or mandated by schools may not yield the optimal experiences for young people. Instead, the benefits of sports participation are contingent on intrinsic mechanisms, including adolescents' perceived sporting ability as well as the importance or meaning attached to their choice of sport. Adolescents who participate in sport participate because sport interests them and is meaningful to them, and self-appraisal of their sport ability confirms likely success. Furthermore, youth who participate less in sport may have intrinsic reasons for participating less; they may lack interest or motivation for a sport that holds little value to them. If sport participation becomes mandatory or coercive, and not meaningful, it may not offer the same positive experiences for youth and could result in a trajectory that is negative rather than positive. This highlights the importance for schools and community programs to provide adolescents with a broader selection of activity alternatives so that adolescents may choose an activity, and not necessarily a sport, which is meaningful to them. Furthermore, schools who stipulate mandatory sport participation as a requirement of their extracurricular programs may need to consider the implications of such programs for adolescents with motivations not well aligned with sport. Notably, in the broader context of physical activity and health, many schools provide physical education within the primary curricular framework in order to educate children about healthy behaviour, and provide them with opportunities to be active. Nonetheless, and as this current study suggests, when designing and implementing extracurricular sport programs for adolescents, it is important to consider under what circumstances children experience positive outcomes.

\section{Limitations}

The results of the current study should be considered in light of its limitations. One of the study's central limitations is the cross-sectional nature of the data that does not allow for causal or temporal interpretations regarding the associations among the constructs. Further, 
although this study's model fits the data well, there may be alternative models that fit the data equally well that have not been assessed here. For instance, it is plausible that a reciprocal relationship exists such that adolescents who have high levels of positive experiences in sport also begin to value their sport more and in turn begin to see themselves as being good at their sport (Eccles., 2009).

\section{Conclusions}

Overall, the present study highlights the complexities surrounding sport participation as a context for psychological benefits. The psychological benefits of sport participation are not inevitable; participation does not automatically guarantee positive experiences. Positive developmental experiences depend on the fit between the values and motivations of athletes and the sporting environment in which they are embedded. If the sport environment is a good match to adolescents' motivations in sport, then positive developmental experiences are more frequent. The results of this study highlight the importance of considering the role of individual differences among athletes when examining the impact of sport on positive development. A promising place to begin is with particular motivations in sport, as the more personally invested and engaged an individual is in their sporting activity, the more psychological gain may accrue. Research should continue to take an individual differences approach to adolescents' sport engagement, to better disentangle the specific contexts that render the most benefits for particular adolescents, because the experiences gained from sports participation are not uniform for all adolescents. 


\section{References}

Australian Bureau of Statistics. (2012). Children's participation in cultural and leisure activities (cat No. 4901.0). Canberra: ABS. Retrieved from http://www.abs.gov.au/ausstats/abs@.nsf/Products/4901.0 Apr+2012 Main+Features Sports+participation?OpenDocument\#

Barber, B. L., Abbott, B. D., Blomfield, C. J., \& Eccles, J. S. (2009). Secrets of their success: Activity participation and positive youth development. In R. Gilman \& M. Furlong (Eds.), Handbook of positive psychology in the schools (pp. 273-289). Lawrence Erlbaum Associates.

Barber, B. L., Stone, M. R., \& Eccles, J. S. (2010). Protect, prepare, support, and engage: The roles of school-based extracurricular activities in students' development. In J. L. Meece \& J. S. Eccles (Eds.), Handbook of Research on Schools, Schooling, and Human Development (pp. 366-378). New York: Routledge.

Barber, B. L., Stone, M. R., Hunt, J. E., \& Eccles, J. S. (2005). Benefits of activity participation: The roles of identity affirmation and peer group norm sharing. In J. L. Mahoney, R. W. Larson, \& J. S. Eccles (Eds.), Organized activities as contexts of development: Extracurricular activities, after-school and community programs (pp. 185-210). Mahwah, NJ: Lawrence Erlbaum.

Blomfield, C. J., \& Barber, B. L. (2009). Brief report: Performing on the stage, the field, or both? Australian adolescent extracurricular activity participation and self-concept, Journal of Adolescence, 32, 733-739.

Bollen, K. A. (1989). Structural Equations with Latent Variables. New York: John Wiley \& Sons, Inc. 
Cohen, J., Cohen, P., West, S.G., \& Aiken, L.S. (2003). Applied multiple regression/correlation analysis for the behavioural sciences. Mahwah, NJ: Lawrence Erlbaum.

Collins, W. A., Maccoby, E. E., Steinberg, L., Hetherington, E. M., \& Bornstein, M. H. (2000). Contemporary research on parenting: The case of nature and nurture. American Psychologist, 55, 218-232.

Csikszentmihalyi, M. (1990). Flow: The Psychology of Optimal Experience. Harper and Row, New York.

Csikszentmihalyi, M., \& Csikzsentmihalyi, I. S. (Eds.). (1988). Optimal Experience: Psychological studies of flow in consciousness. Cambridge, United Kingdom: Cambridge University Press.

Csikszentmihalyi, M., \& Rochberg-Halton, E. (1981). The Meaning of Things: Domestic Symbols and the Self. Cambridge: Cambridge University Press.

Dawson, J. F., \& Richter, A. W. (2006). Probing three-way interactions in moderated multiple regression: Development and application of a slope difference test. Journal of Applied Psychology, 91, 917-926.

De Haan, L. G., \& MacDermid, S (1999). Identity development as a mediating factor between urban poverty and behavioural outcomes for junior high school students. Journal of Family and Economic Issues, 20, 123-148.

Dworkin, J. B., Larson, R., \& Hansen, D. (2003). Adolescents' accounts of growth experiences in youth activities. Journal of Youth and Adolescence, 32,17-26.

Eccles, J. S. (1987). Gender roles and women's achievement-related decisions. Psychology of Women Quarterly, 11, 135-172.

Eccles, J. S. (2008). Agency and structure in human development. Research in Human Development, 5(4), 231-243. 
Eccles, J. S. (2009). Who am I and what am I going to do with my life? Personal and collective identities as motivators of action. Educational Psychologist, 44(2), 78-89.

Eccles, J. S. \& Barber, B. L. (1999). Student council, volunteering, basketball, or marching band: What kind of extracurricular involvement matters? Journal of Adolescent Research, 14, 10-43.

Eccles, J. S., Barber, B. L., Stone, M., Hunt, J. (2003). Extracurricular activities and adolescent development. Journal of Social Issues, 59(4), 865-889.

Eccles, J. S. \& Harold, R. D. (1991). Gender differences in sport involvement: Applying the Eccles' expectancy-value model. Journal of Applied Sport Psychology, 3, 7- 35.

Eccles, J. S., \& Midgley, C. (1989). Stage/environment fit: Developmentally appropriate classrooms for early adolescents. In R. Ames \& C. Ames (Eds.), Research on motivation in education (Vol.3, pp. 139-181). New York: Academic Press.

Eccles, J. S., Midgley, C., Wigfield, A., Buchanan, C. M., Reuman, D., Flanagan, C., \& MacIver, D. (1993). Development during adolescence: The impact of stageenvironment fit on adolescents' experiences in schools and families. American Psychologist, 48, 90-101.

Eccles, J. S., Adler, T. F., Futterman, R., Goff, S. B., Kaczala, C. M., Meece, J. L., \& Midgley, C. (1983). Expectancies, values, and academic behaviors. In J. T. Spence (Ed.), Achievement and achievement motivation (pp. 75-121). San Francisco, CA: W.H. Freeman \& Co.

Erikson, E. (1968). Identity: Youth and crisis. New York: Norton.

Feldman, A. F., \& Matjasko, J. L. (2005). The role of school-based extracurricular activities in adolescent development: A comprehensive review and future directions. Review of Educational Research, 75, 159-210. 
Fredricks, J. A., \& Eccles, J. S. (2006). Is extracurricular participation associated with beneficial outcomes? Concurrent and longitudinal relations. Developmental Psychology, 42(4), 698-713.

Hansen, D. M., \& Larson, R. W. (2007). Amplifiers of developmental and negative experiences in organized activities: Dosage, motivation, lead roles, and adult-youth ratios. Journal of Applied Developmental Psychology, 28(4), 360-374.

Hansen, D. M., Larson, R. W., \& Dworkin, J. B. (2003). What adolescents learn in organized activities: A survey of self-reported developmental experiences. Journal of Research on Adolescence, 13, 25-55.

Jackson, S. A. (1995). Factors influencing the occurrence of flow state in elite athletes. Journal of Applied Sport Psychology, 7, 136-166.

Jackson, S. A. (1996). Toward a conceptual understanding of the flow experience in elite athletes. Research Quarterly for Exercise and Sport, 67, 76-90.

Jackson, S. A., \& Eklund, R. C. (2002). Assessing flow in physical activity: the flow state scale-2 and dispositional flow scale-2. Journal of Sport \& Exercise Psychology, 24, $133-150$.

Jackson, S. A., Ford, S. K., Kimiecik, J. C., \& Marsh, H. W. (1998). Psychological correlates of flow in sport. Journal of Sport and Exercise Psychology, 4, 358-378.

Jackson, S. A., \& Marsh, H. W. (1996). Development and validation of a scale to measure optimal experience: The Flow State Scale. Journal of Sport and Exercise Psychology, $18,17-35$.

Jackson, S. A., \& Roberts, G. C. (1992). Positive performance states of athletes: Toward a conceptual understanding of peak performance. The Sport Psychologist, 6, 156-171.

Jones, R. M., \& Hartmann, B. R. (1988). Ego identity: Developmental differences and experimental substance use among adolescents. Journal of Adolescence, 11, 347-360. 
Jones, R. M., Hartmann, B. R., Grochowski, C. O., \& Glider, P. (1989). Ego identity and substance abuse: A comparison of adolescents in residential treatment with adolescents in school. Personality and Individual Differences, 10, 625-631.

Kleiber, D. A. \& Kirshnit, C. E. (1991). Sport involvement and identity formation. In Diamant, L. (Ed), Mind-body maturity: Psychological approaches to sports, exercise, and fitness (pp. 193-211). Washington, DC: Hemisphere.

Larson, R. (2000). Toward a psychology of positive youth development. American Psychologist, 55, 170-183.

Larson, R., Hansen, D. M., \& Moneta, G. B. (2006). Differing profiles of developmental experiences across types of organized youth activities. Developmental Psychology, 42, 849-863.

Larson, R., \& Verma, S. (1999). How children and adolescents spend time across the world: Work, play, and developmental opportunities. Psychological Bulletin, 25, 701-736.

Lerner, R.M., \& Castellino, D.R. (2002). Contemporary developmental theory and adolescence: Developmental systems and applied developmental science. Journal of Adolescent Health, 31, 122-135.

Lerner, R.M., \& Lerner, J.V. (1987). Children in their contexts: A goodness of fit model. In J.B. Lancaster, J. Altmann, A.S. Rossi, \& L.R. Sherrod (Eds.), Parenting across the lifespan: Biological dimensions (pp 377 - 404). Chicago: Aldine.

Mahoney, J., \& Bergman, L. (2002). Conceptual and methodological considerations in a developmental approach to the study of positive adaptation. Applied Developmental Psychology, 23, 195-217.

Mahoney, J. L., Harris, A. L., \& Eccles, J. S. (2006). Organized activity participation, positive youth development, and the over-scheduling hypothesis. Social Policy Report, 20(4), 3-31. 
Marsh, H., \& Kleitman, S. (2002). The effects of participation in sport during the last two years of high school. Sociology of Sport Journal, 10, 18-43.

Ryan, R. M., \& Deci, E. L. (2000). Self-determination theory and the facilitation of intrinsic motivation, social development, and well-being. American Psychologist, 55, 68-78.

Scanlan, T. K., Babkes, M. L., \& Scanlan, L. A. (2005). Participation in sport: A developmental glimpse at emotion. In J. L. Mahoney, R.W. Larson, \& J. S. Eccles (Eds.), Organized activities as contexts of development: Extracurricular activities, after-school and community programs (pp. 275-311). Mahwah, NJ: Erlbaum.

Schuler, J., \& Brunner, S. (2009). The rewarding effect of flow experience on performance in a marathon race. Psychology of Sport \& Exercise, 10, 168-174.

Sharp, E. H., Coatsworth, J. D., Darling, N., Cumsille, P., \& Ranieri, S. (2007). Gender differences in the self-defining activities and identity experiences of adolescents and emerging adults. Journal of Adolescence, 30, 251-269.

Stein, G. L., Kimiecik, J., \& Jackson, S. A. (1995). Psychological antecedents of flow in recreational sport. Personality and Social Psychology Bulletin, 21, 125-135.

Theokas, C., Almerigi, J.B., Lerner, R.M., Dowling, E.M., Benson, P.L., Scales, P.C., \& Von Eye, A. (2005). Conceptualizing and modeling individual and ecological asset components of thriving in early adolescence. Journal of Early Adolescence, 25(1), 113-143.

Tiggemann, M., \& Slater, A. (2001). A test of objectification theory in former dancers and non-dancers. Psychology of Women Quarterly, 25, 57-64.

Waterman, A. S. (1990). Personal expressiveness: Philosophical and psychological foundations. Journal of Mind and Behavior, 11, 47-74. 
Waterman, A. S. (1992). Identity as an aspect of optimal psychological functioning. In G. R. Adams, T. P. Gullotta, \& R. Montemayor (Eds.), Adolescent identity formation: Advances in adolescent development (pp. 50-72). Newbury Park, CA: SAGE.

Wigfield, A. (1994). Expectancy-value theory of achievement motivation: A developmental perspective. Educational Psychology Review, 6, 49-78.

Wigfield, A., \& Eccles, J. S. (1992). The development of achievement task values: A theoretical analysis. Developmental Review, 12, 265-310. 